\title{
Teaching Minor Surgical Procedures in Internship in Primary Care: A Necessary Approach
}

\author{
Marcelo Tsuyoshi Yamane ${ }^{1}$, Fernanda Pombo Rodriguez ${ }^{1}$, Jessica Belei Martins ${ }^{1}$, Vinicius Klettenberg Machado ${ }^{1}$, \\ Leonardo Campos Teixeira ${ }^{1}$, Maria Rosa Machado Prado ${ }^{1}$ \\ ${ }^{1}$ Faculdades Pequeno Príncipe, Brazil \\ Correspondence: Maria Rosa Machado Prado, Faculdades Pequeno Príncipe, Brazil.
}

Received: November 29, 2019

Accepted: January 15, $2020 \quad$ Online Published: January 18, 2020

doi:10.11114/jets.v8i3.4639

URL: https://doi.org/10.11114/jets.v8i3.4639

\begin{abstract}
Skin and subcutaneous lesions (nevus, fibromas, lipomas), lacerations, ingrown toenails, abscesses, musculoskeletal disorders such as arthritis, bursitis, trigger points, neuropathies and tendinitis are the main causes of problems in primary care that can be resolved with minor procedures. Performing these procedures is an important part of the general practitioner's competencies. The National Medical Course Curriculum Guidelines in Brazil show that medical students should be aware of these diagnostic and therapeutic procedures, based on current literature. In addition to the financial benefits, performing minor procedures in primary care also reduce patient anxiety, has greater convenience due to the proximity and familiarity with the health facility, requires less waiting for treatment, and allows for complete patient care. This paper is an experience report, with the objective of reporting the teaching-learning process during the internship of Family and Community Medicine of the Faculdades Pequeno Príncipe, regarding the performance of outpatient procedures in the primary health care. During the internship, it was possible to perform small procedures such as skin lesion excision, Intrauterine Device (IUD) insertion and trigger point needling. Thus, it is concluded that the teaching of small procedures is an essential part of the medical curriculum and helps to form a physician who addresses the most common complaints of patients in primary care.
\end{abstract}

Keywords: small surgical procedures, internship and residency, competences-based education

\section{Introduction}

Skin and subcutaneous lesions (nevus, fibromas, lipomas), lacerations, ingrown toenails, abscesses, musculoskeletal disorders such as arthritis, bursitis, trigger points, neuropathies and tendinitis are the main causes of problems in primary care that can be resolved with minor procedures (Menahem, Nazarenko \& Shvartzman, 2014). Performing these procedures is an important part of the general practitioner's competencies (Nasmith \& Franco, 1997). According to the National Primary Care Policy, special attention is given for the Care Coordination functions, which includes, besides clinical consultations and home visits, minor surgical procedures (Brasil, 2012). Thus, it is essential that primary health care centers are capable for performing minor clinical and surgical procedures, receiving users in acute or chronic situations, assessing the risks of the underlying disease and the need for urgent care or referral for other health services (Brasil, 2011).

The National Curriculum Guidelines of the Medical Course in Brazil also discuss about the performing these procedures. According to this document, medical students must have a generalist, humanist, critical and reflective background. Graduates should work at different levels of health care, with emphasis on primary care. They should also practice medicine using diagnostic and therapeutic procedures based on scientific evidence and perform indispensable clinical and surgical procedures for care of chronic and emergency situations (Brasil, 2014).

It is essential that the minor procedures performed in primary care are protocol-based, considering the technical capacity of professionals, availability of equipment, materials and medicines. These procedures should be performed with the interdisciplinary team, legitimizing the capacity of all health professionals. One of the protocols is the Primary Care Booklet, which describes some procedures related to the most common diseases in health facilities, based on protocols and scientific evidence found in the literature (Brasil, 2011).

In order to ensure that doctors at the primary attention units are qualified to perform minor procedures, the The College of Family Physicians Canada, for example, requires as one of the accreditation criteria that all residency training programs 
teach these skills. There seems to be general agreement in the literature about which procedures should be provided in primary care. These include cyst excision and skin lesions, wound sutures, intrauterine contraceptive device insertion, cantoplasty, and joint injections. A British study estimated savings of $£ 15.000$ in one year if a family and community doctor performed four weekly procedures (Nasmith \& Franco, 1997).

In addition to the financial benefits, performing small procedures in primary care reduces patient anxiety, as the procedure is performed by the family doctor and not by an unknown doctor, has greater convenience due to the proximity and familiarity with the health unit, lower waiting time for treatment and financial savings, since procedures performed in primary care clinics are cheaper than hospital ones (Menahem, Nazarenko and Shvartzman, 2014).

However, there are still few health facilities that perform these procedures. Lack of time and training were the main reported barriers to their achievement (Menahem, Nazarenko and Shvartzman, 2014). Thus, continuing education must be present in primary care, so that professionals can improve their skills. A Croatian study looked at the effect of the surgical training course on the performance of minor surgical procedures in family practice doctors' offices. The study showed that GPs felt more confident treating comedones, abscesses, ingrown toenails, and skin lesions in their offices. In addition, the urban or rural location of the office was not associated with the number of procedures. This suggests that when it comes to minor surgical procedures in primary practice, the urban and rural population receive a similar level of medical care (Gmajnić, 2008).

One of the most commonly performed procedures in primary care is the resection of skin lesions. Some studies have shown that family doctors performed as well, if not better, than epidermoid carcinoma (SCC) specialists (Delaney, 2012). Other research has shown that melanoma excisions by general practitioners appeared to be of similar quality to those performed by specialists (Murchie, 2011). Dermatoses are frequent complaints, representing high demand in the basic health network. Non-dermatologist physicians, particularly those working in Primary Care, where most dermatological diseases should be treated, need to be able to diagnose and adopt the best course of action for prevalent dermatoses, those at risk of becoming malignant, or those who are at risk have systemic repercussions. The most frequently seen dermatoses in Brazil are: acne, superficial mycoses, pigmentation disorders, actinic keratosis, contact dermatitis, seborrheic dermatitis, viral warts, melanocytic nevi, dermatitis, eczema, dyshidrosis and pityriasis alba. Thus, it is essential that the general practicioner make a differential diagnosis of these lesions, so that he can confirm or rule out malignant diseases and be able to treat them properly (Bernardes, 2015). A study of US medical undergraduates from 2002 to 2003 showed that they do not have sufficient opportunities to observe, learn, and practice the skin cancer exam. When asked about alternatives for improving medical education, they expressed the importance of repetition and emphasis on the prevalent dermatoses throughout the course, as well as the need for congresses and workshops on this specialty (Hymowitz, 2006).

Another procedure that can be performed in primary care is the insertion of the Intrauterine Device (IUD). This type of device is more effective and economical in preventing unwanted pregnancies than most other contraceptive methods. Access to IUDs appears to be limited by the lack of experienced community professionals in the insertion of these devices. A recent analysis of Australia's primary care consultations indicated that only $6.9 \%$ of all contraceptive consultations reported use of Long-Acting Reversible Contraception (LARC). A global review of barriers to widespread use of IUDs among nulliparous women identified that the attitudes of health professionals have the most profound effect on the low rate of women with the device. Thus, ongoing training programs are essential for the training of primary care physicians (Stewart, 2016). One of the strategies that can be used is realistic simulation that allows the student to visualize, question and validate information before experiencing the practice (Yamane, 2019).

Myofascial pain is one of the problems that can be managed with a minor procedure in primary care with needling. Myofascial pain syndrome is an entity characterized by muscle pain localized in a certain area of the body, which progresses even in the absence of laboratory findings. This process originates in muscle points, known as trigger points, which can generate local and referred pain spontaneously or to digital pressure. The prevalence of myofascial pain varies in the population. Studies point to 21 to $30 \%$ in general medicine services and up to $93 \%$ in specialized pain centers, affecting men and women equally. Some of the currently used treatments for myofascial pain include the use of drugs, physical therapy and acupuncture techniques. One of the most effective techniques for trigger point inactivation is needling, which can be done dry or by injecting substances, and is an easy-to-apply technique that can be performed by primary care professionals and can lead to pain relief and improved quality of life (Culpi, 2018).

For these reasons, the present study aims to report the teaching-learning experience during the internship of Family and Community Medicine of the Faculdades Pequeno Príncipe, about the performance of small procedures in a primary attention unit. How these procedures are part of the routine in the primary care setting, medical students should experience this opportunity during internship. In this paper, it was chosen to report some minor procedures that the students had contact with. 


\section{Method}

The internship is the moment when the medical students have the opportunity to experience the reality of the profession, as they deal with the patients in different clinical situations. In this experience report, the students of the 11th year of the Medical School of the Faculdades Pequeno Príncipe, located in Curitiba-Paraná, Brazil, during the internship performed minor procedures on patients of the basic health unit, under the supervision of a teacher.

In order to perform the experience report, they were divided into three stages: at the first, explanations of how to perform the procedures were made. Second, students performed the following procedures with the teacher's supervision: excision of skin lesions, intrauterini contraceptive insertion and micro needling to relieve myofascial pain.

And the third, was performed at the end of each minor surgical procedure, where the teacher made a feedback with the group of students in order to deepen the teaching of these skills and thus provide a better learning.

\section{Results}

In the Primary Health Care Center were the work was made, in addition to the team of doctors, nurses, nursing technicians and staff of the Family Health Support, there is the Family and Community Medicine residency and medical students from Faculdades Pequeno Príncipe. The students have the opportunity to learn essential skills of the general practitioner, such as clinical patient care, home care, participation in smoking groups, emergency primary care workshops, and minor procedures under the full-time supervision of the preceptor.

Among the procedures performed by the students are skin lesion excision, insertion of intrauterine device and microneedling. The Competence-Based Curriculum of the Brazilian Society of Medicine separates the skills for performing outpatient procedures into essential, desirable, and advanced. Thus, IUD insertion and withdrawal is a core competency, outpatient surgical procedures such as shave, punch, or excisional biopsy are desirable competencies and trigger point needling is an advanced competency (SBMFC, 2014).

Among the cutaneous lesion excision procedures, the students performed the removal of a seborrheic keratosis (Figure 1). The procedure was performed by the medical student and the resident, under the supervision of the preceptor. After local anesthesia, an incision was made in the pedicle of the lesion and an incision was made according to the skin tension lines for better aesthetic results. Then a 3-0 Nylon suture was performed and a 7 day return was requested to remove the stitches. The surgical specimen was placed in formaldehyde solution and sent pathological analysis.

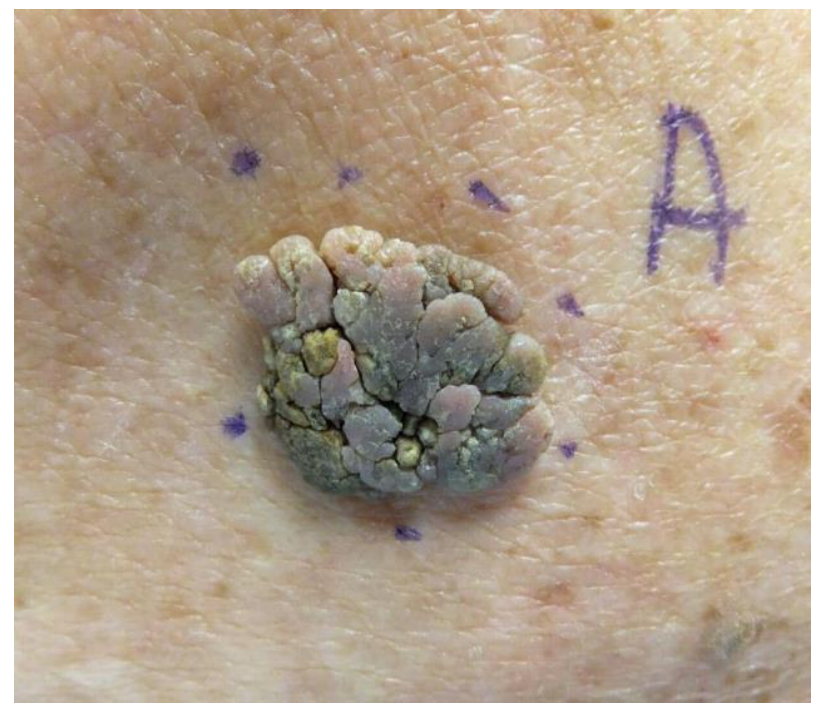

Figure 1. Seborrheic keratosis removed

Students also had the opportunity to insert the IUD under the supervision of a preceptor in the outpatient setting, with no need for sedation. Although most of the time the insertion of this device is performed by other professionals such as the gynecologist or the specialist nurse himself, it is also the responsibility of the family doctor to perform this procedure.

Trigger point needling is also a procedure performed by students in the Family and Community Medicine boarding school (Figure 2). Several diseases and musculoskeletal disorders such as arthritis, bursitis, trigger points, neuropathies, and tendonitis are common complaints in primary care. In this case presented, a patient who came to the health unit sought medical attention complaining of back pain refractory to simple analgesics, presenting trigger points found in the physical examination with immediate improve after the needling. 


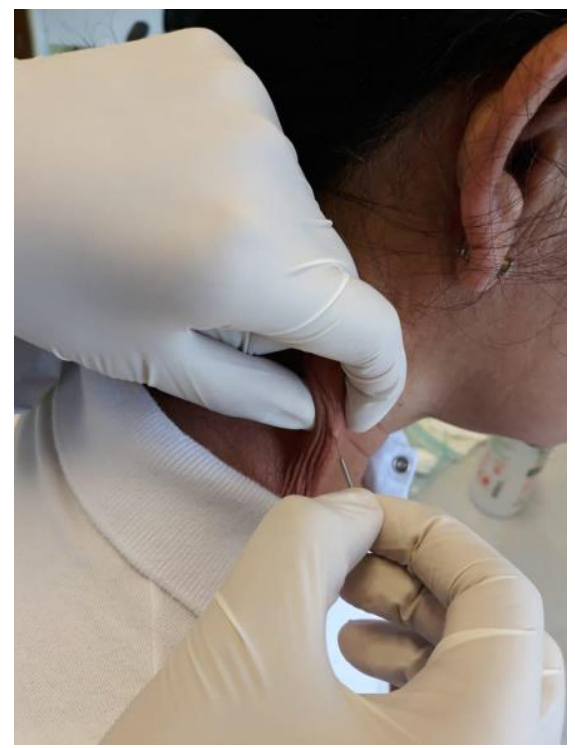

Figure 2. Trigger point needling

\section{Discussion}

The Faculdades Pequeno Príncipe (FPP) adopts as one of the teaching methodologies the Problem Based Learning (PBL), first implemented at the McMaster University Medical School in the 1960s by Barrows and Tamblyn, which has caused a revolution in medical education. PBL is an innovative and challenging approach to medical education because it places the student as a protagonist in the teaching-learning process and requires the teacher to use facilitating skills for teaching (Faisal, Bahadur, \& Shinwari, 2016). For learning to be enhanced it is essential that active methodologies are present in every medical degree, including internship. In this way, undergraduate students are assured of internship teaching through realistic simulations, $360^{\circ}$ assessment, Problem Based Interview (PBI) and performing surgical procedures with subsequent feedback from colleagues and the preceptor. During the internship students have the opportunity to train in different scenarios of medicine practice such as general surgery, gynecology and obstetrics, pediatrics, urgency and emergency and family and community medicine. The internship in Family and Community Medicine is held at the Abranches Primary Care Center, which allows medical students to perform minor procedures under the supervision of a family doctor.

Procedures such as skin lesion excision are resource-poor and can be performed in the primary care setting. How we have already written above, it is one of the competences of the general practitioner. The procedure performed by medical students, for example, required only a small procedure box, a scalpel, lidocaine, and suture line. Thus, it did not require hospitalization and allowed full follow-up of the patient. The only disadvantage is the need for an agreement with a pathology laboratory, which is not a reality in all municipalities of Brazil.

As for the insertion of the IUD, the cost of each device is very low, about US 30,00. Insertion requires few materials such as Pozzi forceps, Sheron forceps and hysterometer. Thus, because they are sterile materials one of the disadvantages of performing this procedure in primary care is the need of a person for sterilization of the materials. However, centers that do not have this space may use inexpensive disposable clamps and hysterometers. Prior to the insertion of the device into practice, students had the opportunity to perform simulations in laboratories with high fidelity mannequins. Simulation prior to the start of practical activity is essential to ensure students' confidence as well as it is safe and ethical because it does not use real patients for learning. Besides that, simulation allows the procedure to be performed several times under the supervision of a teacher who can give a feedback to the student about what can be improved.

Micro-needling is not an expensive procedure either because it does not require expensive materials or sterilization as the needles are disposable. The cost of each needle is about 16 cents. Diagnosing myofascial pain in the elderly is critical to avoid potentially harmful unnecessary diagnostic tests and invasive procedures. (HALTER, 2009) Non-drug treatment consists of measures of postural correction, stretching and dry needling. With the definitive treatment performed in the health center, the cost to the health system was lower, as well as providing better comfort for the patient because he was released on the same day and was followed up in an environment near his home.

Medical Education has changed around the world. Traditional teaching, where the teacher is only the transmitter of knowledge, is no longer compatible with health needs. This is why large medical schools try to develop and implement learning built on the exercise of learning by doing, on the constant relationships between theory and practice, and on 
creative thinking and meaningful learning. Thus, performing small procedures in primary care under constant preceptor supervision and critical analysis is essential for the improvement of competences for medical graduation.

\section{Conclusion}

Teaching small procedures at the boarding school is possible and essential in the medical curriculum, helping to form an egress physician who addresses the most common complaints of patients in primary care. These procedures are part of the family doctor's competences and coping with health vulnerabilities, because they bring convenience to the patient and lower costs. Thus, they offer advantages to the patient and the health system. Conducting these procedures in the primary care setting can improve the doctor-patient relationship and allow doctors to broaden the scope of their work.

\section{References}

Bernardes, C., et al, (2015). Dermatological Diagnoses and Procedures in a Primary Care Unit. Revista Brasileira de Educação Médica, 39(1), 84-94.

Brasil. (2011). Ministério da Saúde. Secretaria de Atenção à Saúde. Departamento de Atenção Básica. Procedimentos / Ministério da Saúde, Secretaria de Atenção à Saúde, Departamento de Atenção Básica. - Brasília: Ministério da Saúde.

Brasil. (2012). Ministério da Saúde. Secretaria de Atenção à Saúde. Departamento de Atenção Básica. Política Nacional de Atenção Básica / Ministério da Saúde. Secretaria de Atenção à Saúde. Departamento de Atenção Básica. - Brasília: Ministério da Saúde.

Brasil. (2014). Resolução nº 3, de 20 de junho de 2014. Institui Diretrizes Curriculares Nacionais do Curso de Graduação em Medicina e dá outras providências.

Culpi, M., \& Martineli, A. (2018). Points Deactivation in the Treatment of Myofascial Pain. Rev Bras Med Fam Comunidade, 13(40), 1-9. https://doi.org/10.5712/rbmfc13(40)1777

Delaney, E. K. (2012). Excising squamous cell carcinomas: comparing the performance of GPs, hospital skin specialists and other hospital specialists. Family Practice, 29, 541-546. https://doi.org/10.1093/fampra/cms007

Faisal, R., Bahadur, S., \& Shinwari, L. (2016). Problem-based learning in comparison with lecture-based learning among medical students. J Pak Med Assoc, 66(6), 650-653.

Gmajnić, R., Pribić, S., Lukić, A.,2 Ebling, B., Čupić, N., \& Marković, I. (2008). Effect of Surgical Training Course on Performance of Minor Surgical Procedures in Family Medicine Physicians' Offices: An Observational Study. Croat Med J., 19, 358-363. https://doi.org/10.3325/cmj.2008.3.358

Halter, Jeffrey B. et al. (2009). Hazzard's Principles of Geriatric Medicine and Gerontology. Mcgraw-hill, (pp.1664).

Hymowitz, M. (2006). Evaluation of Medical Students' Knowledge, Attitudes, and Personal Practices of Sun Protection and Skin Self-examination. Arch Dermatol, 142, 523-524. https://doi.org/10.1001/archderm.142.4.523

Menahem, I., Nazarenko, S., \& Shvartzman, P. (2014). Minor surgical procedures and musculoskeletal injections by primary care physicians - an Israeli experience. Israel Journal of Health Policy Research, 3(12), 1-8. https://doi.org/10.1186/2045-4015-3-12

Murchie, P., \& Lee, E. (2015). Primary excision of cutaneous melanoma: does the location of excision matter. British Journal of General Practice, 61, 131-134. https://doi.org/10.3399/bjgp11X556272

Nasmith, L., \& Franco, C. E. D. (1997). Minor surgical procedures Faculty development workshop. Can Fam Physician, $43,715-718$.

SBMFC. (2014). Currículo Baseado em Competências para Medicina de Família e Comunidade. 2014. Retrieved from: http://www.sbmfc.org.br/wpcontent/uploads/media/CurriculoBaseadoemCompetencias.pdf

Stewart, M. (2016). Outcomes of intrauterine device insertion training for doctors working in primary care. Royal Australian College of General Practitioners, 45(11), 837-841.

Yamane, M. (2019). Realistic simulation as a teaching tool in health: an integrative review. Revista Espaço para Saúde, 20(1), 87-107. https://doi.org/10.22421/15177130-2019v20n1p87

\section{Copyrights}

Copyright for this article is retained by the author(s), with first publication rights granted to the journal.

This is an open-access article distributed under the terms and conditions of the Creative Commons Attribution license which permits unrestricted use, distribution, and reproduction in any medium, provided the original work is properly cited. 